\title{
Vegetarian Eco-feminist Consciousness in Carol Ann Duffy's Poetry
}

\author{
Jie Zhou \\ School of Applied English Studies, Shandong University of Finance and Economics, China
}

Received: 04-05-2015

Accepted: 08-07- 2015

Published: 31-07-2015

doi:10.7575/aiac.ijclts.v.3n.3p.38

URL: http://dx.doi.org/10.7575/aiac.ijclts.v.3n.3p.38

The research is financed by the Humanity and Social Science Project "Feminist Study of Carol Ann Duffy's Poetry"of Ministry of Education in China, No. 11YJA752033.

\begin{abstract}
This paper discusses vegetarian eco-feminist consciousness in Carol Ann Duffy's poetry by close analysis of two poems, namely "The Dolphins" and "A Healthy Diet" from her poem collection Standing Female Nude. The former is a dramatic monologue of a dolphin, which is exploited by people, and the latter is a dramatic monologue of an omnipotent observer in a restaurant. Both poems criticized the species-ism, and together, they showed the poet's vegetarian eco-feminist consciousness. A close reading of the two poems from the eco-feminist perspective helps the reader understand why Carol Ann Duffy is honored as the first woman poet laureate in British history, and better understand vegetarian eco-feminism and its influence in British society.
\end{abstract}

Keywords: eco-feminism; consciousness, species-ism, vegetarian, animal, diet

\section{Introduction}

Carol Ann Duffy, the first woman poet laureate in British history, is not only noticed as a feminist poet (Rees-Jones, 1999; Michelis \& Rowland, 2003; Zhou, 2013, 2014), but also studied as a poet with sympathy for people living in the margin of the society (Aydin,2010). In Zhou's feminist analysis of Carol Ann Duffy's poetry, Duffy is found to be a lover of nature with eco-feminist consciousness. Further readings of Duffy's poetry discovers Duffy as not only with sympathy for the people in the margin in the society, but also with concern for animals that are ill-treated, under the influence of species-ism, a kind of "prejudice or attitude of bias in favor of the interests of members of one's own species and against those of members of another species" (Singer, 1975, p6). In Standing Female Nude, Duffy showed vegetarian eco-feminist consciousness, and called for animal protection and vegetarianism in two poems, namely "The Dolphins", calling for animal liberation from being captured and trained for commercial performance, and "A Healthy Diet", calling for vegetarianism by criticizing human beings for eating animals. By close reading of the two poems from the eco-feminist perspective, this paper aims to help the reader better understand the present British poet laureate as a poet of eco-feminist viewpoints and her sympathy for all living beings in the world.

\section{Eco-feminism, Species-ism and Vegetarian Eco-feminism}

According to Gaard, eco-feminism can be traced in the "work of women gardeners, outdoor enthusiast, environmental writers, botanists, scientist, animal welfare activists, and abolitionist over the past two centuries" (2002, p. 117). The 1980s saw the shaping of eco-feminism in the movement with a combination of the idea of peace, antinuclear and feminism. In the following two decades, eco-feminism developed in different directions.

The concept of species-ism was first popularized in Animal Liberation (1975) by Peter Singer. With the development of eco-feminism, species-ism is criticized as a form of oppression of human being as a species of privilege over other animals. Because of its agreement to the practices of animal hunting and animal sacrifice ever since human history begins, species-ism is criticized by some critics including Léonie Caldecott and Stephanie Leland in Reclaim the Earth (1983), and by Irene Diamond and Gloria Feman Orenstein in Reweaving the World (1990). Furthermore, Greta Gaard in Ecofeminism: Women, Animals, Nature (1993) states:

Most poeple who are not born into a vegetarian culture but become vegetarians by choice do so based on their sympathy for other animals. Today the facts of animal suffering are well known. In U.S. laboratories between seventeen million and seventy million animals are killed every year. In factory farming operations six billion animals suffer and die annually — sixteen million each day. Dairy cows are regularly separated from newborn calves so that their milk can go to humans while their infants are chained in tightly fitting crates for four months and fed an iron-deficient diet until they are slaughtered. Chickens are debeaked and crowded five to each sixteen-by-eighteen-inch cage, their natural life spans of fifteen to twenty years shortened to two. Pigs are confined in narrow steel stalls with concrete floors, while sows are kept in a continual cycle of pregnancy, birth, and artificial insemination, their piglets taken away from them before they have even had the chance to suckle (Gaard, pp. 118-119). 
The above facts of animal suffering, including separation of newborn animals from their mothers, being chained and debeaked and crowded and shortened in lifespan, being confined and fed for the purpose of more births of the newborn, are facts of human greed and cruelty, more exactly speaking, facts of the commitment of species-ism by human beings, and facts shown in Carol Ann Duffy's poems like "The Dolphins" and "A Healthy Diet" from her poem collection Standing Female Nude. They show the poet's sympathy for the animals and criticism of species-ism.

Adams (1991) sees the consumption of meat as synonymous with the exercise of male power over women. Accordingly, women's adoption of vegetarian food-ways has been considered as a challenge to male dominance. A six-year survey of first year undergraduates and their meat consumption, undertaken by Alan Beardsworth and Alan Bryman (1999), discovered that women account for the majority of vegetarians. Women were found to be more likely to be vegetarians and eat less meat. In comparison, men were more likely to eat more or the same amount of meat. This result echoes with many other study results, some of which have attributed the result to the cultural association between the consumption of meat with male dominance, and is a challenge to or rejection of the "macho" aspects of masculinity (Adams, 1991).

According to Gaard, "if eco-feminism can be seen as the offspring of feminism, then vegetarian eco-feminism is surely feminism's third generation"(2002, p.117). Vegetarian eco-feminism developed with "a recognition of the inadequacies of feminist and eco-feminist analyses". Vegetarian eco-feminists "examines the political contexts of dietary choices as well as strategic and operational choices in science and economics" (Gaard, 2002, p.117). Hoon also argues for the consistency for feminism to become vegetarian eco-feminism beyond eco-feminism, so that feminism can implement its original spirit to abolish all forms of the logic of domination (2011: 205-231).

By “A Healthy Diet", Duffy advocates vegetarianism for the protection of animals, for which meat-eating is criticized as a "form of patriarchal domination" in the 1972s in lesbian feminists' criticism. As a lesbian, her advocates of vegetarianism is thus understandable.

\section{Species-ism in "The Dolphins"}

In "The Dolphins", Duffy gives the animals a chance to speak for themselves, exposing the ill-treatment they get from human beings, who capture them and exploit them. A strong eco-feminist consciousness is shown in her description of the dolphins as being able to think, to speak, to remember, and to have feelings and religious belief. Distinguished from human beings, dolphins live in water, a world of "what you swim in, or dance"(line 1), and "Outside this world you cannot breathe for long"(line 3). The dolphins are shown as being equal to human beings in the presentation of the ability to think: the speaking dolphin is able to look at the other one, and tell that "The other has my shape. The other's movement/ forms my thoughts"(lines 4-5). The dolphin is clear that they "are not free", despite of being in their "element" (line 2). She/He is able to explore the cause of their loss of freedom, as shown in "There is a man / and there are hoops", and is able to feel, as shown in "There is a constant flowing guilt"(line 6). The dolphin is even of religious belief, as shown as able to decide that "We have found no truth in these waters, / no explanation tremble on our flesh" (lines 7-8), just like Christians in search of truth, and can show regret for their wrong doings. Human beings are shown as of no sense of guilt in using tools like hoops to train the dolphins, as shown in "no explanation tremble on our flesh"(line 8). In the dolphin's understanding of their fate, "We were blessed and now we are not blessed"(line 9). The process of their fate's change is described in his/her memory, "after traveling such space for days we began / to translate" (lines 10-11), an obvious picture of them captured by human beings from their home water and have to move to a strange place. They are no longer able to swim around freely, "It was the same space. It is the same space always and above it is the man"(lines 11-12), taking control of their fate. Their life is not blessed because the water is too shallow for them and they can no longer dream. All they can find is the reflection of each other in the other dolphin and the speaking dolphin, recalling their past by looking at each other's silver skin. Day by day, they are forced to play with a coloured ball in balance, as the man above orders and human beings enjoy watching them. Their life under the control of human being is in sharp contrast with their free days, because "the moon has disappeared" (line 20) while they are always indoors. Their life is monotonous, circling the "grooves of water on a single note"(line 21). The other dolphin feels a loss, and the speaking dolphin's heart is turned into stone. "There is no hope" (line 22) except for a plastic toy, because they have to "sink to the limits of this pool until the whistle blows"(line 23) each day. Originally they are clever dolphins, but after being captured and trained, they have to follow the man's order, and in order to survive, they have to obey him, because "there is a man", and they "will die" there (line 24).

According to Brian Luke, there are many ways of animal abuse,

shooting, trapping, and poisoning; branding, castrating, forcibly impregnating, separating mother and young, tail docking, debeaking, confining, transporting in cattle cars, and slaughtering; burning, cutting, gassing, starving, asphyxiating, decapitating, decompressing, irradiating, electrocuting, freezing, crushing, paralyzing, amputating, excising organs, removing parts of the brain, socially isolating, inducing addiction, and imposing disease (Luke, in Adams and Donovan, 1995, p.79, p.81).

The dolphins are trapped, captured, transported from their home, and socially isolated from other dolphins, confined and asphyxiated, and forced to perform, etc. The poem, in the viewpoint of dolphin, reveals the sufferings and sadness in their hopeless life, calling on people to give them freedom and stop classifying animals as in a "lower" position, and human beings as in a higher position, which ignores the welfare and dignity of animals, because this equals to the commitment of destruction and brutality. 


\section{Vegetarianism in "A Healthy Meal"}

Carol Ann Duffy creates an omnipotent observer, who makes a dramatic monologue in the poem "A Healthy Meal", criticizing people as inhuman for taking animal meat, showing her vegetarian eco-feminist consciousness. The opening lines, "The gourmet tastes the secret dreams of cows / tossed lightly in garlic" (lines 1-2) implies that the cows are once eaten, with their dreams turning into a secret. The oxtails are shown as "languish", as if of life but losing life "on an earthen dish"(line 3). When the wishbones and pinkies become food for human beings and are put on the table, people are guilty of killing animals though they wash their hands in the finger bowls. The expression "capped teeth" is used to refer to people who chew animal kidney or bird breast, exposing the fact that animals are so maltreated when alive that their hearts "knew no love", and later, when put on the saffron rice, they show complaint towards people for their brutal and loveless heart. The question about what claret is like draws people's attention, and "Blood" as an answer is severe criticism of people's cruelty. Then the speaker focuses attention on one table, on which "the language of tongues is braised in Armagnac" (line 9-10), indicating that animals are of tongues and of their own languages, just like us human beings, but they are deprived of equal rights to human beings and turned into food for people.

By personalizing animals in the poem, Duffy shows animals as equal to human beings, who is superior to animals because of power, and turn out to be as cruel as wild animals. The picture of the woman "chewing chuckling pig" and "must sleep with her husband later"(lines 10-11) shows her as of animal instinct of eating meat and making love. The picture of "a fat man" ordering his rare (line 15), with sweat on the face, with the words "There are napkins to wipe the evidence"(line 16), can be considered as evidence of swear and having eaten animals, revealing and echoing with the word "guilt" in the opening stanza. The speaker personalizes the animal by saying "Leg, / saddle and breast bleat against pure white cloth"(lines 11-12), as if these animals can make noises to show their sufferings. The "groans" these animals make in the abattoirs emphasizes the pain of the animals, which are personalized. The order "alter calf to veal" (line 13) also shows the power of people, who can enjoy everything, including lights, a knife for an animal's tripe, and charcuterie, where animal meat is sold. The menu "lists the recent dead in French" (line 18) exposes the fact that people have been killing animals for food. The line "Death moves in the bowels" (line 20) makes the reader vomit. Finally, the speaker says "You are what you eat" (line 20) to directly criticize human beings as equal to animals, and meanwhile shows the speaker's opposition towards people who eat animal meat. This obvious criticism of species-ism not only calls on people's sympathy for the animals being eaten by human beings, but also calls for people to stop consumption of animal meat for food.

With "A Healthy Meal", the poet describes the pain of animals, fated to be killed and eaten by human beings, and exposes human being's crime of killing and eating animals. According to Greta Gaard (1993), it's not proper for animal meat to become food for human beings, especially for the purpose of nutrition. As for other reasons for vegetarianism, or eating no animal meat, she listed the following: first, vegetarianism can reduce the grain used to feed animals so as to feed more people in the world; two, vegetarianism can reduce ecological destruction caused by the increasing animal agriculture; three, vegetarianism can reduce chances of diseases in human beings caused by meat-based diet; four, vegetarianism can reduce animals' sufferings and their loss of life to provide human beings as food. Therefore, it is not only unhealthy, but also unethical and unsympathetic. Nor is it ecological-friendly for animal meat to be taken as food for human beings. The poem "A Healthy Meal" exposes human brutality in killing and eating animals as an unsympathetic behavior, which is criticized as an ethical problem, a bloody crime, torturing animals to death, and turning human beings into animals themselves at the same time.

\section{Conclusion}

In the two poems analyzed above, Carol Ann Duffy exposes the cruelty of human species for taking advantage of other species of nonhuman nature, capturing and training them for exploitation or killing and eating them for nutrition purposes. The exposure shows her criticism of species-ism and vegetarian eco-feminist consciousness.

\section{References}

Adams, J. C. (1991). Eco-feminism and the Eating of Animals. Hypatia, 6(1), 134.

Aydin, O. (2010). Speaking from the Margins: The Voice of the 'Other' in the Poetry of Carol Ann Duffy and Jackie Kay. Cambridge: Maunsel \& Co.

Beardsworth, A. \& Bryman, A. (1999). Meat consumption and vegetarianism among young adults in the UK: An empirical study. British Food Journal, 101(4), 289 - 300.

Caldecott, L. \& Leland, S.(1983). Reclaim the Earth: Women Speak Out for Life on Earth. London: Women's Press.

Hoon, C. (2011). Feminism and Vegetarianism. Korean Feminist Philosophy, 15, 205-231.

Diamond, I. \& Gloria F. O. (1990). Reweaving the World.New York: Random House.

Duffy, C. A.(1985) . Standing Female Nude. London: Anvil.

Gaard, G. (2002). Vegetarian Eco-feminsim: A Review Essay. Frontiers: A Journal of Women Studies, 23(3),117-146.

Zhou, J. (2013). A Feminist Study of Carol Ann Duffy's Poetry, Xiamen: Xiamen University Press.

Luke, B. (1995). Justice, Caring, and Animal Liberation in Animals and Women: Feminist Theoretical Explorations, ed. Carol J. Adams and Josephine Donovan, Durham NC: Duke University Press, pp.79-81. 
IJCLTS 3 (3):38-41, 2015

Michelis, A., \& Rowland, A. (eds.)(2003). The Poetry of Carol Ann Duffy: Choosing Tough Words. Manchester: Manchester University Press.

Rees-Jones, D. (1999). Carol Ann Duffy, Plymouth: Northcote House.

Singer, P. (1975). Animal Liberation. New York: Harper Collins. 